\title{
Difference in Therapeutic Alliance: High-Conflict Co-Parents vs Regular Couples
}

Andrea Mae Parady

Brigham Young University

Follow this and additional works at: https://scholarsarchive.byu.edu/etd

Part of the Marriage and Family Therapy and Counseling Commons

\section{BYU ScholarsArchive Citation}

Parady, Andrea Mae, "Difference in Therapeutic Alliance: High-Conflict Co-Parents vs Regular Couples" (2018). Theses and Dissertations. 6995.

https://scholarsarchive.byu.edu/etd/6995

This Thesis is brought to you for free and open access by BYU ScholarsArchive. It has been accepted for inclusion in Theses and Dissertations by an authorized administrator of BYU ScholarsArchive. For more information, please contact scholarsarchive@byu.edu, ellen_amatangelo@byu.edu. 
Difference in Therapeutic Alliance: High-Conflict

Co-Parents vs Regular Couples

Andrea Mae Parady

A thesis submitted to the faculty of

Brigham Young University

in partial fulfillment of the requirements for the degree of

Master of Science

Shayne R. Anderson, Chair

Angela Beesley Bradford

Lee N. Johnson

School of Family Life

Brigham Young University

Copyright (C) 2018 Andrea Mae Parady

All Rights Reserved 


\author{
ABSTRACT \\ Difference in Therapeutic Alliance: High-Conflict \\ Co-Parents vs Regular Couples \\ Andrea Mae Parady \\ School of Family Life, BYU \\ Master of Science
}

The purpose of this research is to explore differences in the therapeutic alliance for HighConflict Co-Parents (HCC) vs. Regular Couples. Therapeutic alliance refers to the relationship, consisting of a bond, and agreement on the tasks and goals of therapy, between at least two people in the therapeutic relationship. It was hypothesized that HCC clients would have lower therapeutic alliance scores compared to regular couple clients. The results supported this hypothesis. By identifying these differences, more research can be conducted to improve our understanding of how to strengthen the therapeutic alliance with HCC clients, leading to improved treatment of this population.

Keywords: alliance, couples, therapy, divorce 


\section{ACKNOWLEGEMENTS}

I would like to thank Shayne R. Anderson, my faculty advisor and chair, for his constant guidance and patience. Thank you for believing in me and helping me achieve something that I didn't always believe was possible. Thank you for also teaching me the statistical analyses that I didn't know. Without you, I wouldn't have been able to complete this thesis. I would also like to thank my committee members, Lee Johnson and Angela Bradford. Thank you for your feedback and support throughout the process of writing this thesis.

I would also like to acknowledge my husband Jevin, who made this whole journey possible. Thank you for encouraging me and supporting me in my pursuit of higher education. I am so grateful for your never-ending love. Thank you for making all of my hopes and dreams come true. 


\section{TABLE OF CONTENTS}

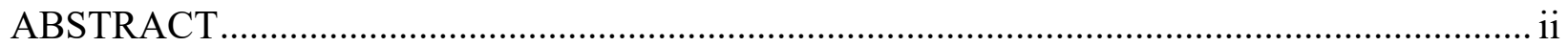

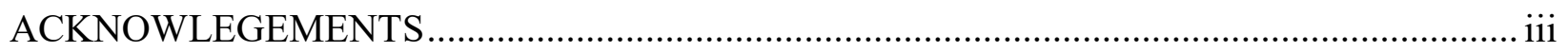

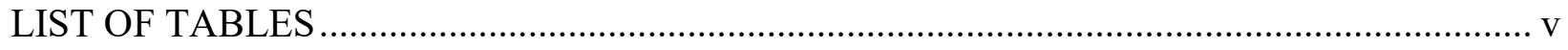

Difference in Therapeutic Alliance: High-Conflict Co-Parents vs Regular Couples ................... 1

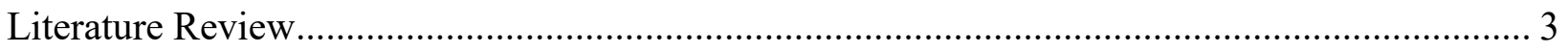

Importance of the Therapeutic Alliance .................................................................. 3

Mandated Co-parenting Therapy as a Predictor of Alliance Formation............................... 4

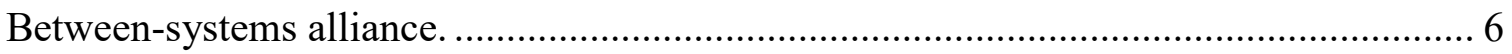

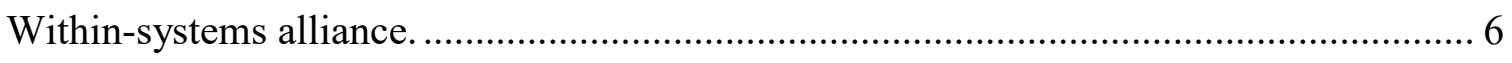

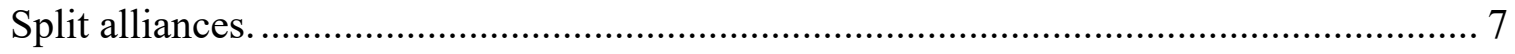

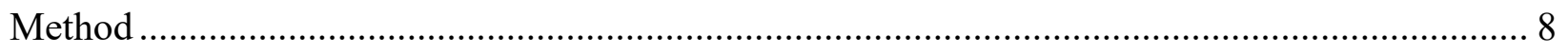

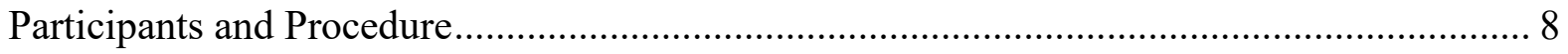

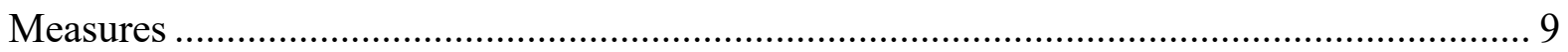

Couple Therapy Alliance Scale Revised-Short Form ................................................ 9

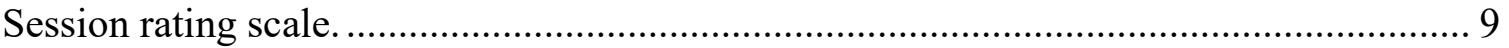

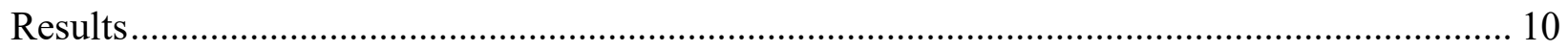

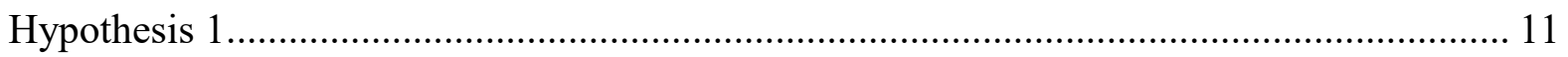

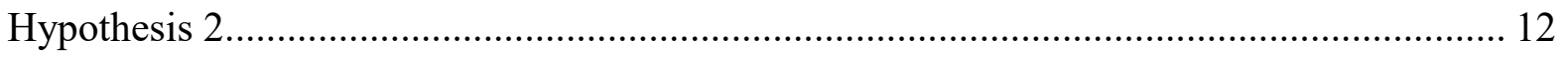

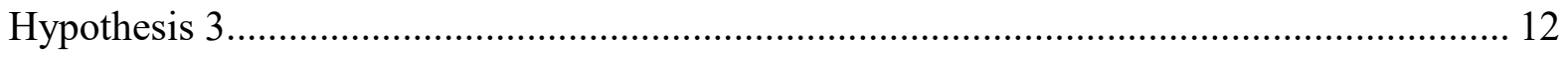

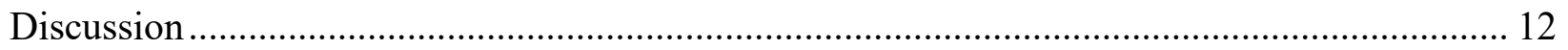

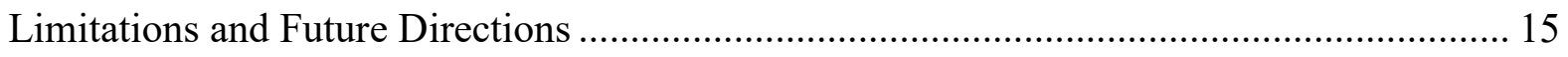

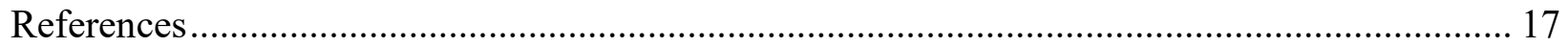




\section{LIST OF TABLES}

Table $1 \mathrm{t}$-tests for variables associated with being HCC or regular couples............................. 24

Table 2 Summary of Simple Regression Analyses for Variables Predicting Alliance scores on the Session Rating Scale for Males and Females....................................... 25

Table 3 Summary of Simple Regression Analyses for Variables Predicting Alliance scores on the Couples Therapeutic Alliance Scale for Males and Females .................. 26

Table 4 Summary of Simple Regression Analyses for Variables Predicting Within-systems Alliance for Males and Females

Table 5 Summary of Simple Regression Analyses for Variables Predicting Split

Alliance for Males and Females 


\section{Difference in Therapeutic Alliance: High-Conflict \\ Co-Parents vs Regular Couples}

The U.S. has a high incidence of divorce with approximately $43 \%$ to $46 \%$ of marriages likely to end in divorce (Amato, 2010). While divorce is a stressful transition, most families adjust to the divorce over time without help from professionals and experience decreased conflict following the initial divorce transition (Emery, 1999; Walsh, Jacob, \& Simon, 1995). A small percentage of families, however, will continue to litigate long after the divorce decree is finalized, or will demonstrate intractable conflict throughout the divorce or child custody proceedings (Maccoby, Mnookin, Depner, \& Peters, 1992; Neff \& Cooper, 2004;). These "high conflict" co-parents (HCC) are characterized by the pervasiveness of the conflict as well as the hostile, insecure emotional environment (Anderson, Anderson, Palmer, Mutchler, \& Baker, 2011) and take up an inordinate amount of the court system's time, particularly when they become physically violent (Braver, Sandler, Hita, \& Wheeler, 2016; Neff \& Cooper, 2004; Spillane-Grieco, 2000). These cases are detrimental to the health and well-being of all parties involved, but particularly to the children who are often the focus of parental conflict (Haddad, Phillips, \& Bone, 2016). In hopes of preventing these deleterious outcomes, courts, attorneys, and child protective services will often refer these families to conjoint co-parenting therapy to improve communication and decrease their conflict (Johnston 1994; Johnston 2006).

Since HCC dyads rarely initiate treatment themselves (Scharff, 2006), they are not often voluntary, which can make it more difficult to work with this population. Many of the clinicians that work with these clients express that it is harder to work with them, because the therapist is seen as part of the court system. This causes the clients to not trust the therapist entirely or 
causes the clients to use him/her as an ally against the other parent with each partner trying to gain the support of the therapist rather than working through the actual problems (Honea-Boles \& Griffin, 2001; Scharff, 2006). Research on individuals who are court referred or courtmandated shows that it is more difficult to create and maintain a strong therapeutic alliance with these non-voluntary clients (Barrett \& Rappaport, 2011; Honea-Boles \& Griffin, 2001). Part of this difficulty is due to the struggle between care and control, with care being the services provided to the client and control being the decision-making power over the client or force that the therapist can exert (Manchak, Skeem, \& Rook, 2014; Ungar \& Ikeda, 2017). This struggle, along with clients coming with different goals for treatment, suggest that it is more difficult for therapists to build strong alliances with HCC clients. Indeed, therapists that work with HCC client have expressed that frequently the clients view an alliance between one parent and the therapist as an alliance against the other parent (Lebow \& Reckart, 2007).

While the research shows that it is more difficult to form a strong therapeutic alliance with non-voluntary individual cases, and anecdotally therapists report that it is harder to create an alliance with HCC cases, this same claim has not been evaluated empirically for courtreferred HCC cases. Since the therapeutic alliance is a robust predictor of positive therapy outcomes, it is important to understand how the development of the alliance may differ with HCC cases. When a clinician has a strong bond with their clients' and they agree on the goals and tasks of therapy, there is more positivity, success, and positive outcomes (Beutler \& Harwood, 2002; Bordin, 1979; Darwiche, et al., 2008; Horvath \& Symonds, 1991; Knerr, et al., 2011; Knobloch-Fedders, Pinsof, and Mann, 2004, 2007). Understanding these differences in forming alliances with HCC cases is the first step in developing specific strategies and 
interventions for addressing problems in the alliance formation and maintenance and, consequently, to help therapists improve clinical outcomes for these kinds of clients.

\section{Literature Review}

\section{Importance of the Therapeutic Alliance}

Bordin (1979) offered the most widely adopted conceptualization of the therapeutic alliance. He proposed that the alliance has three different domains: a bond between the clients and therapist, agreement on tasks, and agreement on goals. The bond is how the client feels in their relationship with the therapist, while agreement on tasks and goals focuses on agreeing on what should be done to achieve certain agreed upon outcomes (Bordin, 1979). Later, Pinsof (1994) expanded the idea of the alliance to address the multiple relationships intrinsic to working with couples and families. He said that the therapeutic alliance includes "those aspects of the relationships between and within the therapist and patient systems that pertain to their capacity to mutually invest in and collaborate on the tasks and goals of therapy" (p. 176). The between systems alliance refers to the multiple individual alliances formed between each member of the family system and the therapist. In any family system, and particularly with HCC cases, it is likely that the quality of these alliances will differ across family members. Substantial differences (sometimes considered differences greater than one standard deviation) are referred to as split alliances (Heatherington \& Friedlander, 1990; Knobloch-Fedders et al., 2007;

Mamodhoussen, Wright, Tremblay, and Poitras-Wright, 2005; Pinsof, 1994). The within system alliance reflects the degree to which family members agree on what needs to be accomplished in therapy, how the goals should be accomplished and their ability to collaborate toward accomplishing those goals. 
While no research has examined whether the alliance predicts success working with HCC clients, there is a significant body of research showing that the alliance predicts outcomes across multiple presenting problems and multiple treatment modalities (Horvath \& Symonds, 1991; Martin, Garske, \& Davis, 2000; Friedlander, Escudero, Heatherington, \& Diamond, 2011). Many other studies have also found that agreement on tasks and goals is correlated with better treatment and therapeutic outcomes as well (Darwiche et al., 2008; Knobloch-Fedders et al., 2007). In addition, Knerr and associates (2011) said about the therapeutic alliance that it is "the most important determinant in treatment continuance and success as well as... contributing to the outcome of therapy" (p. 183). Horvath and Symonds (1991) conducted a meta-analysis (containing 24 studies using individual therapy) that remarkably found that $26 \%$ of the difference in success of therapy was explained by the quality of therapeutic alliance. Darwiche and colleagues (2008) conducted a study of mutual smiling episodes between couples and their therapist and found that when the couple and the therapist have strong therapeutic alliance there is greater positivity in session and better therapy outcomes. Another study found that the therapeutic alliance predicted couple progress in therapy and the outcomes of therapy for that couple (Knobloch-Fedders et al., 2007). Lastly, Bordin (1979) also found that the strength of the alliance predicted the effectiveness of therapy more than the type of alliance. All of these studies and many others have found that the therapeutic alliance is strongly correlated with positive outcomes and success in therapy (Beutler \& Harwood, 2002; Knobloch-Fedders et al., 2004).

\section{Mandated Co-parenting Therapy as a Predictor of Alliance Formation}

While the link between alliance and outcome has been well-established, much less is known about factors that predict the development of a strong alliance in couple or dyadic treatment. One likely predictor is whether a family was mandated to attend treatment. Mandated 
therapy is therapy that is requested or ordered by a third party, such as a court, where the individuals being mandated can expect negative consequences for refusing to attend or comply (Honea-Boles \& Griffin, 2001). More often HCC cases are soft-mandated rather than courtmandated. Moore, Tambling, and Anderson (2013) defined soft-mandated clients as people "who experience pressure to attend therapy yet do not face severe consequences for therapy nonattendance" (249). In essence, clients who are mandated to attend therapy receive more pressure to attend therapy than the average client, regardless of whether it is court- or softmandated. HCC cases often fall into this category of court- or soft-mandated clients because they rarely seek treatment of their own volition (Johnston, 1994; Johnston, 2006; Scharff, 2006).

When HCC dyads are mandated or pressured into attending therapy it has been assumed that there is a negative effect on the alliance (Johnston, 1994; Johnston, 2006, Scharff, 2006;). Research that has examined pressure to attend therapy in traditional couple or family therapy has found it to be a significant predictor of the quality of the therapeutic alliance, with pressure to attend being negatively correlated with alliance (Bartle-Haring et al., 2011; Knobloch-Fedders et al., 2004). While these findings likely generalize to the alliance with HCC cases, it has not been examined empirically.

Along with pressure to attend therapy, the alliance is also complicated by the number of people attending each session (Knerr et al., 2011). As mentioned earlier, in couples' therapy, there are three important aspects of the therapeutic alliance to consider: within-systems, between-systems, and split alliances, (Jurek, Janusz, Chwal, \& de Barbaro, 2014; Pinsof, 1994; Pinsof, 1995). Due to the intense, intractable nature of conflict in HCC cases, the pressure to attend therapy and low relationship satisfaction, it is likely that HCC cases will differ from 
traditional couple therapy in how the alliance forms in each of these areas (Anderson et al., 2011; Johnston, 1994, Johnston, 2006).

Between-systems alliance. The between-systems alliance is the collaborative working relationship between the therapist and each individual client in the system (Anderson \& Johnson, 2010). A strong bond with the clients is built when clients can feel safe with the therapist. This safety is not likely to occur in court mandated therapy for HCC because the therapist is seen as an enemy who is not to be trusted because they are part of the court system (Honea-Boles \& Griffin, 2001; Scharff, 2006). In couple's therapy, one client might have a strong betweensystems alliance, while the other client has a weak between-systems alliance; this is called a split alliance and will be discussed in greater detail later (Jurek et al., 2014). Additionally, since these clients are court-referred, it is likely that their primary goal (complete the referral to demonstrate compliance) differs from the therapist's (improve client communication and conflict resolution). This difference in goals between the therapist and clients would be reflected in poor betweensystems alliance. The between-systems alliance can be measured in two ways: self-therapist, which is each individual's rating of their own alliance with the therapist; and other-therapist, which is the person's view of their spouse or other person and the therapist (Pinsof, Zinbarg, \& Knobloch-Fedders, 2008).

Within-systems alliance. The within-systems alliance is the sense of a shared purpose within the family (Friedlander, Lambert, \& de la Pena, 2009). In one study, couples often cited safety as a crucial precondition for change (Christensen, Russell, Miller, \& Peterson, 1998). This safety is not likely to occur with a HCC dyad that is locked in conflict. Jurek and associates (2014) found that lack of hope contributes to dropout as well, which lack of hope can be because they attribute the failure and problems to just one partner, which is part of a poor within-systems 
alliance. Marital distress is also a factor in low within-systems alliance, which HCC clients have as an inherent part of their case (Knobloch-Fedders et al., 2004). Bartle-Haring and colleagues (2012) conducted a study that showed that couples that can quickly come to an agreement about the therapeutic alliance are more successful in therapy. This agreement is not likely to occur with HCC dyads because they are caught in pervasive, hostile conflict (Anderson et al., 2011). This lack of agreement is predictive of a lower within-systems alliance, as well as an increased occurrence of split alliances.

Split alliances. A split alliance is formed when one between-systems alliance is weak while the other is strong (Jurek et al., 2014). Many studies have found a connection between split alliances and dissatisfaction, and dropout (Blow et al., 2009: Jurek et al., 2014). Therapists working with HCC dyads often struggle with split alliances because when the therapist strengthens the alliance with one partner, the other partner may see it as an alliance against them (Lebow \& Reckart, 2007).

With the correlation between high marital distress and poor within-systems alliances and more split alliances, we can expect HCC clients to experience split alliances and poor withinsystems alliances more frequently than the regular couples attending therapy. Due to these challenges, it is likely that HCC clients will have lower total alliances and, consequently, higher dropout in the initial stages of therapy compared to regular couples. While the literature suggests these relationships, they have not been examined empirically. The present study will examine the following hypotheses:

a) HCC clients will have lower total alliances compared to regular couples

b) HCC clients will have lower within systems alliances compared to regular couples

c) HCC clients will have greater number of split alliances compared to regular couples 


\section{Method}

\section{Participants and Procedure}

Data were collected for this study at the on-campus training clinic of a COAMFTE accredited Marriage and Family Therapy program in the Northeast United States. The clinic serves members of the community, faculty, and students at the university. The current sample includes all cases that presented for couple therapy or HCC treatment from 2010 to 2014. Of the 233 dyads, 92 were HCC clients, and 141 were couples therapy clients who were self-referred, which we will call regular couples. Their ages ranged from 18-77 (female Mean: 33.54, SD: , male Mean: 35.47, SD: ). All clients who attended the clinic provided demographic information and completed measures of individual and relational distress prior to treatment. Immediately following the first session of therapy clients completed two measures of the therapeutic alliance. The clinic has a long relationship with the family court system that refers $\mathrm{HCC}$ clients to the clinic for treatment. Clients were primarily White (76.4\%), Latino/a (8.2\%), Asian (6.1\%), Other (4.5\%), and African American/Black (3.5\%). The majority of the sample had at least some college education $($ male $=51.1 \%$; female $=63.9 \%$ ). Income was broken down as follows: less than $\$ 19,999=16.96 \%, \$ 20,000-59,999=27.04 \%, \$ 60,000+=26.18 \%$, with $6.87 \%$ not knowing their income and $22.95 \%$ missing.

At the clinic, a battery of instruments was administered on the first and every fourth session clients were seen. Data were collected with written consent from the clients. Both master's-level and doctoral-level students as well as clinical faculty were the therapists for the clients presenting at the clinic. All student therapists were supervised by licensed Marriage and Family Therapists who were COAMFTE-approved supervisors. 


\section{Measures}

Couple Therapy Alliance Scale Revised-Short Form. Participants completed one of two versions Couple Therapy Alliance Scale Revised-Short Form (CTASr-SF; Pinsof, Zinbarg, \& Knobloch-Fedders, 2008), a 12-item measure of the systemic alliance. Scores were averaged and had a range of 0 to 6 . Regular couples completed the original form $\mathrm{HCC}$ clients completed a version in which the word "partner" was revised to "co-parent" or "other parent". The CTASrSF measures three aspects of the alliance: The alliance between each partner and the therapist (self-therapist), the alliance each partner perceived the other partner having with the therapist (other-therapist), and the alliance between the partners (within). This factor structure was confirmed by Pinsof and colleagues (2008). Pinsof, and colleagues (2008) also found each of these subscales to be reliable: Self/Group $\alpha=.82$, Other $\alpha=.70$, and Within $\alpha=.72$. No reliability was reported for the overall measure, but in the current sample the overall Chronbach's alpa was .94 (male $\alpha=.94$, female $\alpha=.93$ ). The current sample also had high reliability for each of the subscales Self/Group (male $\alpha=.88$, female $\alpha=.90$ ), Other (male $\alpha=$ .91 , female $\alpha=.94$ ), and Within (male $\alpha=.88$, female $\alpha=.85$ ).

Session rating scale. The Session Rating Scale (SRS; Duncan et al., 2003) is a 4-item visual analog measure of the between systems therapeutic alliance that was administered following each session of therapy. The SRS scores range from 0-40. Clients rated each session in four areas: Relationship, Goals and Topics, Approach or Method, and Overall. The SRS was found to be reliable $\alpha=.88$ and has adequate concurrent validity, (Duncan et al., 2003). For the current sample, internal reliability was high (male $\alpha=.87$, female $\alpha=.85$ ).

Two different measures of the alliance were used for a couple of reasons. First, the SRS had less missing data, so it gives a fuller picture of what is occurring. Second, the CTAS has a 
subscale that measures the within-systems alliance, whereas the SRS does not. Another benefit of using two measures is that we can be more confident in the results if they are consistent across the two measures because there is no mono-measure bias. The SRS is administered immediately following the session while the CTAS is administered prior to the next session, so while both capture the clients' perception of the alliance following the first session, they measure two potentially different impressions — an immediate impression of the alliance and the impression of the alliance approximately one week after the session. Thus, both the CTAS and SRS are needed to provide all the data necessary to answer the hypotheses.

Neither of the measures specifically address how to define or measure split alliances. Researchers have measured split alliances in multiple ways, with significant differences in alliance scores being the original definition (Pinsof \& Catherall, 1986). Other studies have operationally defined "notable difference" as differences greater than 1 or 2 standard deviations (SD) of difference in partner's scores on the alliance (Heatherington \& Friedlander, 1990; Knobloch-Fedders et al., 2007; Mamodhoussen et al., 2005). In this study a split alliance is defined as a difference greater than 1 SD away from the mean. To do this I created a new variable where differences greater than 1 SD away from the mean were coded as 1s, which will stand for split alliances and everything else will be coded as 0 s.

\section{Results}

T-tests and chi-squares were used to examine whether HCC clients and regular couples differed significantly on any demographic variables. The results of these tests revealed that there were significant differences between the groups on multiple variables (see table 1 for the full results). Due to these significant group differences, multiple linear regressions and binary logistic regressions were run to test the hypotheses rather than t-tests. Using a multivariate model allows 
me to control for the effects of significant differences between the two groups discussed above by including these variables in a multiple imputations model.

As with any naturalistic study, missing data were prevalent in the current sample. Thirtyfive percent of the sample had missing data on the SRS while $53.65 \%$ had missing data on the CTAS. To diagnose whether the data was missing at random (MAR) or not, t-tests and chisquare analyses were used to examine what variables were associated with missingness. These tests revealed that all of the following were significantly related to missingness: females who had previous experience with therapy, males who thought their problems were the fault of another person, females who believed their problems were caused by their partner, and male anxiety scores were more likely to have missing data. To meet the assumption of MAR, all variables that were associated with missingness were included as predictors in a multiple imputation model. to create $m=50$ imputed datasets. Note that it is a rule of thumb that the number of imputations needed is $M=100 *$ fraction of missing data in highest variable (i.e. $\mathrm{m}=100 * 0.5$; Bodner, 2008; Graham et al., 2007; White, Royston, \& Wood, 2011). Regressions were run to test each hypothesis once the multiple imputations dataset was created. While HCC clients and regular couples differed significantly on both anxiety and depression, in order to prevent the collinearity that would arise from including both of these highly correlated measures in the analyses, male depression and anxiety $r(193)=.73 p<.01$, female depression and anxiety $r(189)$ $=.64 p<.01$, only depression was included in the final regression models.

\section{Hypothesis 1}

To test whether HCC clients have lower total alliances compared to regular couples, I ran separate regressions for male and female partners on each measure of the alliance (see Tables 1 and 2 for full results). After controlling for the other variables in the model, male and female 
$\mathrm{HCC}$ clients scored significantly lower than regular couples on the SRS (female $B=-5.12, \mathrm{p}=.00$; male $B=-5.56 \mathrm{p}=.00)$. After controlling for the other variables in the model, male and female HCC clients scored significantly lower than regular couples on the CTAS $\left(B_{\text {female }}=-.70, p=.00\right.$; $\left.\mathrm{B}_{\text {male }}=-.81, \mathrm{p}=.00\right)$. These results support the hypothesis that HCC clients have lower overall therapeutic alliance scores than regular couples, regardless of the alliance measure used.

\section{Hypothesis 2}

To test whether HCC clients will have lower within-systems alliances compared to regular couples', I ran separate regressions for male and female partners on the within-systems alliance subscale on the CTAS. Even after controlling for the other variables in the model, HCC clients scored significantly lower than regular couples on the within-systems alliance subscale $\left(\mathrm{B}_{\text {female }}=-1.14, \mathrm{p}=.00 ; \mathrm{B}_{\text {male }}=-1.09, \mathrm{p}=.00\right)$. These results support the hypothesis that HCC clients have lower within-systems alliance scores than regular couples.

\section{Hypothesis 3}

To test the final hypothesis, that HCC clients will have a greater occurrence of split alliances compared to regular couples, a binary logistic regression was run. The odds ratio for non-voluntary couples having a split alliance on the SRS was 2.06. This means that HCC clients are twice as likely as regular couples to have a split alliance according to this definition. The odds ratio for HCC clients having a split alliance on the CTAS was 3.18. This means that HCC clients are three times as likely to experience a split alliance compared to regular couples according to this definition.

\section{Discussion}

This study provides evidence for the often-assumed difference in alliances between HCC clients and regular couples. The first hypothesis, that HCC clients would have lower total 
alliance scores than regular couples, was supported by the statistical analyses. The results suggest that there really is a difference and that HCC dyads have lower overall alliances compared to regular couples. This result is not surprising given the body of research which suggests that pressure to attend therapy is associated with lower alliance scores (Glebova, BartleHaring et al., 2011; Knobloch-Fedders et al., 2004; Kuhlman, Tolvanen, \& Seikkula, 2013). These differences were seen at session 1 which is important to note since early alliance is associated with earlier dropout and poorer therapeutic outcomes (Labouliere, Reyes, Shirk, \& Karver, 2017; Yoo, Bartle-Haring, \& Gangamma, 2016). Knowing this, therapists should spend additional time building and strengthening their alliance with these couples. This can be done in several different ways. A qualitative meta-analysis was recently published that explores behaviors that the therapists and/or clients identified as important to building and strengthening the alliance (Lavik, Frøysa, Brattebø, McLeod, \& Moltu, 2017). This study identified 6 therapist behaviors or skills that promote alliance building: (1) balancing technique with warmth, (2) therapist demonstrates a genuine desire to understand their client, (3) therapists making adjustments in their interaction so as to promote safety, (4) the therapist attends to the client's body language, (5) therapist supports client's agency, and lastly (6) therapist provides a constructive first session experience. Their research also identified 5 themes that the client noticed that built/strengthened the alliance: (1) perceiving the therapist as competent and warm, (2) feeling supported, (3) feeling deeply understood by the therapist, (4) experiencing hopefulness, and (5) challenging their apprehension or preconceived fear of therapy. Knowing that HCC clients are more likely to have lower overall alliances than regular couples, therapists can implement some of these behaviors to help strengthen their alliance with these types of clients. 
The second hypothesis, that HCC clients would have lower within-systems alliances, was also supported. This means that HCC clients were less likely than regular couples to report that they have a strong bond or that they agree on the tasks and goals for therapy with their co-parent. This makes sense with this population since HCC clients are divorced and are often referred to therapy due to their intractable conflict (Johnston, 1994, Johnston, 2006; Anderson et al., 2011). In addition, marital distress is known to be associated with lower within-systems alliances, and HCC clients have had (and continue to have) distress in their relationship that led them to end the marriage (Knobloch-Fedders et al., 2004). Knowing this, therapists can work to find common ground/goals that both HCC partners can agree on. This may include working on finding out common things that they want for their children, or focusing on how much they hate the other person and working to not have to see each other as much by resolving some of their differences. This may improve the within-systems alliance as the co-parents begin to work together instead of against each other. Therapists can spend more time finding common ground that unites the coparents instead of divides. The therapist can also work on diminishing the distress in the relationship by working on communication and setting up rules and boundaries that would make therapy a safe place to work through problems (Escudero, Boogmans, Loots, \& Friedlander, 2012). In creating safety in the therapy room, HCC clients might be able to find some stability in their relationship, leading to a stronger within-systems alliance. Overall, this would increase the likelihood of success in therapy (Friedlander et al., 2011; Horvath \& Symonds, 1991; Martin et al., 2000).

The third hypothesis, that HCC clients would have a higher rate of split alliances than regular couples, was also supported. The binomial logistic regression showed that HCC clients have a higher probability of meeting the criteria for having a split alliance than regular couples 
do. This makes sense because as the therapist works to strengthen the alliance with one person, the other co-parent may feel betrayed, weakening the alliance with this other co-parent (Lebow \& Reckart, 2007). This finding is important because of the high correlation between having a split alliance resulting in earlier dropout and dissatisfaction with therapy (Blow et al., 2009: Jurek et al., 2014). Recognizing that HCC clients are more likely to have split alliances, therapists should be prepared to address their role and be careful not to take sides. The therapist should also spend time building a strong alliance with each partner and possibly discuss the split alliance with both co-parents if it occurs. Friedlander, Escudero, \& Heatherington, (2006) suggest that when the therapist is not as skilled in bringing up the split alliance overtly, that more covert interventions may be used to highlight and repair the split alliance. These interventions can include "humor, varying the therapeutic context, and the strategic use of indirectness" (Friedlander, et al., 2006, p. 174). These researchers also suggest avoiding meeting individually with clients because it can cause an imbalance in the alliance.

\section{Limitations and Future Directions}

While the results of this study are useful, there are several limitations that should be noted. The data used in this study had a fair amount of missing data. Another limitation to the generalizability is its small sample size. The sample used was also very specific (HCC clients), which limits the generalizability of the results to other populations that also experience pressure to attend therapy. Another limitation is that the first two hypotheses used independent tests with paired data, which does not give a complete view of the interrelated nature of the dyadic data. Although, the final hypothesis did address the dyadic nature of the data by comparing male and female partner's scores. Finally, the study only looked to see if there were differences in the alliance but does not focus on how to prevent these differences or how to ameliorate their effects. 
These limitations can be addressed in future studies. In those studies, larger and more diverse samples can be collected to increase the generalizability of the results to other populations. For example, research could be conducted on samples that include domestic violence cases, addiction, and many more. Any replication of this study could strengthen the findings and hopefully reduce the overall amount of missing data. To remedy the limitation of dyadic data being analyzed independently, future studies should utilize analyses that explore the dyadic nature of alliance scores. Future studies can also look beyond just finding differences by exploring how to ameliorate the effects of these weak alliances to improve the therapy given to the target population. While it is important to know that there are differences between HCC clients and regular couples, it is more important to know how to improve the alliance both in regular couples' therapy and HCC therapy. Thus far, researchers have failed to address how to fix this problem. Even in the individual therapy literature, there have been many studies that show that the therapeutic alliance is weaker for individuals that experience more pressure to attend therapy, but there is little research giving clinicians guidelines on how to strengthen the alliance with these clients. Future research should address questions such as: (1) what steps can the therapist take to build the alliance in the first session? (2) what can the therapist do to strengthen the within-systems alliance in HCC client sessions? (3) when there is a split alliance, what specific behaviors and interventions can repair the split? Despite these weaknesses, this study is the first to collect data on differences in the therapeutic alliance for HCC clients, paving the way for further research to be conducted. 


\section{References}

Amato, P. R. (2010). Research on divorce: Continuing trends and new developments. Journal of Marriage and Family, 72(3), 650-666. doi:10.1111/j.1741-3737.2010.00723.x

Anderson, S. R., \& Johnson, L. N. (2010). A dyadic analysis of the between- and within-system alliances on distress. Family Process, 49(2), 220-235. doi:10.1111/j.15455300.2010.01319.x

Anderson, S. R., Anderson, S. A., Palmer, K. L., Mutchler, M. S., \& Baker, L. K. (2011). Defining high conflict. American Journal of Family Therapy, 39(1), 11-27. doi:10.1080/01926187.2010.530194

Barrett, J. G., \& Rappaport, N. (2011). Keeping it real: Overcoming resistance in adolescent males mandated into treatment. Adolescent Psychiatry, 1(1), 28-34. doi:10.2174/2210676611101010028

Bartle-Haring, S., Knerr, M., Adkins, K., Delaney, R. O., Gangamma, R., Glebova, T., \& .. . Meyer, K. (2012). Trajectories of therapeutic alliance in couple versus individual therapy: Three-level models. Journal of Sex \& Marital Therapy, 38(1), 79-107. doi:10.1080/0092623X.2011.569635

Beutler, L. E., \& Harwood, T. M. (2002). What is and can be attributed to the therapeutic relationship? Journal of Contemporary Psychotherapy, 32(1), 25-33. doi:10.1023/A:1015579111666

Blow, A. J., Morrison, N. C., Tamaren, K., Wright, K., Schaafsma, M., \& Nadaud, A. (2009). Change processes in couple therapy: An intensive case analysis of one couple using a common factors lens. Journal of Marital and Family Therapy, 35(3), 350-368. doi:10.1111/j.1752-0606.2009.00122.x 
Bodner, T.E. (2008). What improves with increased missing data imputations? Structural Equation Modeling, 15(4), 651-675.

Bordin, E. S. (1979). The generalizability of the psychoanalytic concept of the working alliance. Psychotherapy: Theory, Research \& Practice, 16(3), 252-260. doi:10.1037/h0085885

Braver, S. L., Sandler, I. N., Hita, L. C., \& Wheeler, L. A. (2016). A randomized comparative effectiveness trial of two court-connected programs for high-conflict families. Family Court Review, 54(3), 349-363. doi:10.1111/fcre.12225

Christensen, L. L., Russell, C. S., Miller, R. B., \& Peterson, C. M. (1998). The process of change in couples therapy: A qualitative investigation. Journal of Marital and Family Therapy, 24(2), 177-188. doi:10.1111/j.1752-0606.1998.tb01074.x

Darwiche, J., de Roten, Y., Stern, D. J., von Roten, F. C., Corboz-Warnery, A., \& FivazDepeursinge, E. (2008). Mutual smiling episodes and therapeutic alliance in a therapistcouple discussion task. Swiss Journal of Psychology / Schweizerische Zeitschrift Für Psychologie / Revue Suisse De Psychologie, 67(4), 231-239. doi:10.1024/14210185.67 .4 .231

Duncan, B. L., Miller, S. D., Sparks, J. A., Claud, D. A., Reynolds, L. R., Brown, J., \& . . . Johnson, L. D. (2003). Session rating scale: Preliminary psychometric properties of a "working" alliance measure. Journal of Brief Therapy, 3(1), 3-12.

Emery, R. E. (1999). Marriage, divorce, and children's adjustment., 2nd ed. Thousand Oaks, CA, US: Sage Publications, Inc.

Escudero, V., Boogmans, E., Loots, G., \& Friedlander, M. L. (2012). Alliance rupture and repair in conjoint family therapy: An exploratory study. Psychotherapy, 49(1), 26-37. doi:10.1037/a0026747 
Friedlander, M. L., Escudero, V., Heatherington, L., \& Diamond, G. M. (2011). Alliance in couple and family therapy. Psychotherapy, 48(1), 25-33. doi:10.1037/a0022060

Friedlander, M. L., Lambert, J. E., \& de la Pena, C. M. (2008). A step toward disentangling the alliance/improvement cycle in family therapy. Journal of Counseling Psychology, 55(1), 118-124. doi:10.1037/0022-0167.55.1.118

Glebova, T., Bartle-Haring, S., Gangamma, R., Knerr, M., Delaney, R. O., Meyer, K., \& . . . Grafsky, E. (2011). Therapeutic alliance and progress in couple therapy: Multiple perspectives. Journal of Family Therapy, 33(1), 42-65. doi:10.1111/j.14676427.2010.00503.x

Graham, J. W., Olchowski, A. E., \& Gilreath, T. D. (2007). How many imputations are really needed? Some practical clarifications of multiple imputation theory. Prevention Science, 8(3), 206-213. doi:10.1007/s11121-007-0070-9

Haddad, L., Phillips, K. D., \& Bone, J. M. (2016). High-Conflict Divorce: A Review of the Literature. American Journal of Family Law, 29(4), 243-258.

Heatherington, L., \& Friedlander, M. L. (1990). Couple and family therapy alliance scales: Empirical considerations. Journal of Marital and Family Therapy, 16(3), 299-306. http://dx.doi.org/10.1111/j.1752-0606.1990.tb00851.x

Honea-Boles, P. R., \& Griffin, J. E. (2001). The court-mandated client: Does limiting confidentiality preclude a therapeutic encounter? TCA Journal, 29(2), 149-160.

Horvath, A. O., \& Symonds, B. D. (1991). Relation between working alliance and outcome in psychotherapy: A meta-analysis. Journal of Counseling Psychology, 38(2), 139-149. doi:10.1037/0022-0167.38.2.139 
Johnston, J. R. (1994). High-conflict divorce. The Future of Children, 4(1), 165-182. doi: $10.2307 / 1602483$

Johnston, J. R. (2006). A child-centered approach to high-conflict and domestic-violence families: Differential assessment and interventions. Journal of Family Studies, 12(1), 1535. doi:10.5172/jfs.327.12.1.15

Jurek, J., Janusz, B., Chwal, M., \& de Barbaro, B. (2014). Premature termination in couple therapy as a part of therapeutic process. Cross case analysis. Archives of Psychiatry and Psychotherapy, 16(2), 51-59. doi:10.12740/APP/26962

Knerr, M., Bartle-Haring, S., McDowell, T., Adkins, K., Delaney, R. O., Gangamma, R., \& . . . Glebova, T., Grafsky, E., \& Meyer, K. (2011). The impact of initial factors on therapeutic alliance in individual and couples therapy. Journal of Marital and Family Therapy, 37(2), 182-199. doi:10.1111/j.1752-0606.2009.00176.x

Knobloch-Fedders, L. M., Pinsof, W. M., \& Mann, B. J. (2004). The formation of the therapeutic alliance in couple therapy. Family Process, 43(4), 425-442. doi:10.1111/j.15455300.2004.00032.x

Knobloch-Fedders, L. M., Pinsof, W. M., \& Mann, B. J. (2007). Therapeutic alliance and treatment progress in couple psychotherapy. Journal of Marital and Family Therapy, 33(2), 245-257. doi:10.1111/j.1752-0606.2007.00019.x

Kuhlman, I., Tolvanen, A., \& Seikkula, J. (2013). The therapeutic alliance in couple therapy for depression: Predicting therapy progress and outcome from assessments of the alliance by the patient, the spouse, and the therapists. Contemporary Family Therapy: An International Journal, 35(1), 1-13. doi:10.1007/s10591-012-9215-5 
Labouliere, C. D., Reyes, J. P., Shirk, S., \& Karver, M. (2017). Therapeutic alliance with depressed adolescents: Predictor or outcome? Disentangling temporal confounds to understand early improvement. Journal of Clinical Child and Adolescent Psychology, 46(4), 600-610. doi:10.1080/15374416.2015.1041594

Lavik, K. O., Frøysa, H., Brattebø, K. F., McLeod, J., \& Moltu, C. (2017). The first sessions of psychotherapy: A qualitative meta-analysis of alliance formation processes. Journal of Psychotherapy Integration. Advance online publication. http://dx.doi.org/10.1037/int0000101

Lebow, J., \& Rekart, K. N. (2007). Integrative family therapy for high-conflict divorce with disputes over child custody and visitation. Family Process, 46(1), 79-91. doi:10.1111/j.1545-5300.2006.00193.x

Maccoby, E. E., Mnookin, R. H., Depner, C. E., \& Peters, H. E. (1992). Dividing the child: Social and legal dilemmas of custody. Cambridge, MA, US: Harvard University Press.

Mamodhoussen, S., Wright, J., Tremblay, N., \& Poitras-Wright, H. (2005). Impact of marital and psychological distress on therapeutic alliance in couples undergoing couple therapy. Journal of Marital and Family Therapy, 31(2), 159-169. http://dx.doi.org/10.1111/j.1752-0606.2005.tb01553.x

Manchak, S. M., Skeem, J. L., \& Rook, K. S. (2014). Care, control, or both? Characterizing major dimensions of the mandated treatment relationship. Law and Human Behavior, 38(1), 47-57. doi:10.1037/lhb0000039

Martin, D. J., Garske, J. P., \& Davis, M. K. (2000). Relation of the therapeutic alliance with outcome and other variables: A meta-analytic review. Journal of Consulting and Clinical Psychology, 68(3), 438-450. doi:10.1037/0022-006X.68.3.438 
Moore, L. E., Tambling, R. B., \& Anderson, S. R. (2013). The intersection of therapy constructs: The relationship between motivation to change, distress, referral source, and pressure to attend. American Journal of Family Therapy, 41(3), 245-258. doi:10.1080/01926187.2012.685351

Neff, R., \& Cooper, K. (2004). Parental conflict resolution: Six-, twelve-, and fifteen-month follow-ups of a high-conflict program. Family Court Review, 42(1), 99-114. doi:10.1177/1531244504421008

Pinsof, W. M. (1994). An integrative systems perspective on the therapeutic alliance: Theoretical, clinical, and research implications. In A. O. Horvath, L. S. Greenberg, A. O. Horvath, L. S. Greenberg (Eds.), The working alliance: Theory, research, and practice (pp. 173-195). Oxford, England: John Wiley \& Sons.

Pinsof, W. M. (1995). Integrative problem-centered therapy: A synthesis of family, individual, and biological therapies. New York, NY, US: Basic Books.

Pinsof, W. M., Zinbarg, R., \& Knobloch-Fedders, L. M. (2008). Factorial and construct validity of the revised short form Integrative Psychotherapy Alliance Scales for family, couple, and individual therapy. Family Process, 47(3), 281-301. doi:10.1111/j.15455300.2008.00254.x

Pinsof, W.M., \& Catherall, D. R. (1986). The integrative psychotherapy alliance: Family, couple, and individual therapy scales. Journal of Marital and Family Therapy, 12, 137-151.

Scharff, K. E. (2006). Therapeutic supervision with families of high-conflict divorce. In J. S. Scharff, D. E. Scharff, J. S. Scharff, D. E. Scharff (Eds.), New paradigms for treating relationships (pp. 133-146). Lanham, MD, US: Jason Aronson. 
Spillane-Grieco, E. (2000). Cognitive-behavioral family therapy with a family in high-conflict divorce: A case study. Clinical Social Work Journal, 28(1), 105-119. doi:10.1023/A:1005167926689

Ungar, M., \& Ikeda, J. (2017). Rules or no rules? Three strategies for engagement with young people in mandated services. Child and Adolescent Social Work Journal, 34(3), 259-267. doi:10.1007/s10560-016-0456-2

Walsh, F., Jacob, L., \& Simon, V. (1995). Facilitating healthy divorce processes: Therapy and mediation approaches. In N.S. Jacobson \& A.S. Gurman (Eds.), Clinical handbook of couple therapy (pp. 340-365). New York: Guilford Press.

White, I. R., Royston, P., \& Wood, A.M. (2001). Multiple imputation using chained equations: Issues and guidance for practice. Statistics in Medicine, 30(4), 377-399. https://doi.org/10.1002/sim.4067

Yoo, H., Bartle-Haring, S., \& Gangamma, R. (2016). Predicting premature termination with alliance at sessions 1 and 3: An exploratory study. Journal of Family Therapy, 38(1), 517. doi:10.1111/1467-6427.12031 


\section{TABLES}

Table 1

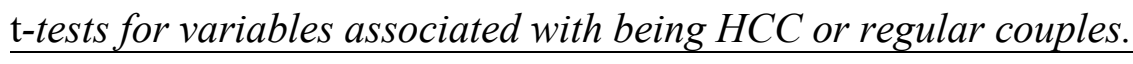

\begin{tabular}{|c|c|c|c|c|c|}
\hline & \multicolumn{2}{|c|}{$\mathrm{HCC}$} & \multicolumn{2}{|c|}{ Regular Couples } & \multirow[b]{2}{*}{$t$-test } \\
\hline & $\mathrm{M}$ & SD & $\mathrm{M}$ & SD & \\
\hline Female Age & 36.70 & 8.52 & 31.40 & 11.87 & $-3.82 *$ \\
\hline Male Depression & 5.07 & 6.01 & 14.84 & 10.95 & $7.99 *$ \\
\hline Female Depression & 7.58 & 8.04 & 15.83 & 10.96 & $6.13^{*}$ \\
\hline Male Anxiety & 3.26 & 4.47 & 6.88 & 5.56 & $5.00^{*}$ \\
\hline Female Anxiety & 4.05 & 4.52 & 7.69 & 5.49 & $5.04 *$ \\
\hline
\end{tabular}

$* p<.01$

Notes. $\mathrm{M}=$ Mean. $\mathrm{SD}=$ Standard Deviation. $\mathrm{HCC}=$ High-Conflict Co-Parents. 
Table 2

Summary of Simple Regression Analyses for Variables Predicting Alliance scores on the Session Rating Scale for Males and Females

\begin{tabular}{|c|c|c|c|c|c|c|c|c|c|c|}
\hline \multirow[b]{3}{*}{ Variable } & \multicolumn{5}{|c|}{ Females } & \multicolumn{5}{|c|}{ Males } \\
\hline & \multirow[t]{2}{*}{$B$} & \multirow[t]{2}{*}{ SE B } & \multirow[t]{2}{*}{$\beta$} & \multicolumn{2}{|c|}{$95 \% \mathrm{CI}$} & \multirow[t]{2}{*}{$B$} & \multirow[t]{2}{*}{$S E B$} & \multirow[t]{2}{*}{$\beta$} & \multicolumn{2}{|c|}{$95 \% \mathrm{CI}$} \\
\hline & & & & Low & High & & & & Low & High \\
\hline Intercept & 39.30 & 2.43 & & 34.52 & 44.07 & 36.79 & 3.01 & & 30.75 & 42.83 \\
\hline Non-voluntary a & $-5.12 * *$ & 1.35 & -.34 & -7.78 & -2.46 & $-5.56^{* *}$ & 1.69 & -.31 & -8.89 & -2.23 \\
\hline Female Age & -.09 & .06 & -.13 & -.20 & .03 & -.09 & .07 & -.13 & -.22 & .05 \\
\hline Male Education $b$ & -.61 & 1.23 & -.04 & -3.02 & 1.81 & -.18 & .25 & -.10 & -.67 & .31 \\
\hline Female & $-.14 *$ & .07 & -.21 & -.28 & -.01 & .05 & .07 & .07 & -.09 & .18 \\
\hline \multicolumn{11}{|l|}{ Depression } \\
\hline Male Depression & -.06 & .07 & -.08 & -.20 & .01 & -.09 & .07 & -.10 & -.23 & .06 \\
\hline$R^{2}$ & \multicolumn{5}{|c|}{0.12} & \multicolumn{5}{|c|}{0.12} \\
\hline$F$ & \multicolumn{5}{|c|}{$7.11 * *$} & \multicolumn{5}{|c|}{$4.58 * *$} \\
\hline
\end{tabular}

Notes. Multiple imputations 50, because of missing data. a reference category is voluntary

$\mathrm{J}_{\mathrm{b}}$ education reference category is no college education.

${ }^{*} p<.05 .{ }^{* *} p<.01$. 
Table 3

Summary of Simple Regression Analyses for Variables Predicting Alliance scores on the Couples Therapeutic Alliance Scale for Males and Females

\begin{tabular}{|c|c|c|c|c|c|c|c|c|c|c|}
\hline \multirow[b]{3}{*}{ Variable } & \multicolumn{5}{|c|}{ Females } & \multicolumn{5}{|c|}{ Males } \\
\hline & \multirow[t]{2}{*}{$B$} & \multirow[t]{2}{*}{$S E B$} & \multirow[t]{2}{*}{$\beta$} & \multicolumn{2}{|c|}{$95 \%$ CI } & \multirow[t]{2}{*}{$B$} & \multirow[t]{2}{*}{$S E B$} & \multirow[t]{2}{*}{$\beta$} & \multicolumn{2}{|c|}{$95 \% \mathrm{CI}$} \\
\hline & & & & Low & High & & & & Low & High \\
\hline Intercept & 5.99 & .38 & & 5.24 & 6.74 & 6.27 & .37 & & 5.54 & 6.99 \\
\hline Non-voluntary a & $-.70 * *$ & .22 & -.33 & -1.13 & -.28 & $-.81 * *$ & .24 & -.37 & -1.29 & -.33 \\
\hline Female Age & -.01 & .01 & -.10 & -.03 & .01 & -.02 & .01 & -.18 & -.04 & .00 \\
\hline Male Education b & .23 & .18 & .11 & -.13 & .59 & -.05 & .17 & -.03 & -.39 & .29 \\
\hline Female & -.01 & .01 & -.11 & -.03 & .01 & .00 & .01 & .04 & -.02 & .02 \\
\hline \multicolumn{11}{|l|}{ Depression } \\
\hline Male Depression & -.00 & .01 & -.02 & -.02 & .02 & -.01 & .01 & -.12 & -.03 & .01 \\
\hline$R^{2}$ & \multicolumn{5}{|c|}{0.13} & \multicolumn{5}{|c|}{0.18} \\
\hline$F$ & \multicolumn{5}{|c|}{$8.14^{* *}$} & \multicolumn{5}{|c|}{$11.30 * *$} \\
\hline
\end{tabular}

Notes. Multiple imputations 50, because of missing data. a reference category is voluntary

]b education reference category is no college education.

${ }^{*} p<.05 .{ }^{* *} p<.01$. 
Table 4

Summary of Simple Regression Analyses for Variables Predicting Within-systems Alliance for Males and Females

\section{Females}

Males

\begin{tabular}{|c|c|c|c|c|c|c|c|c|c|c|}
\hline \multirow[b]{2}{*}{ Variable } & \multirow[t]{2}{*}{$B$} & \multirow[t]{2}{*}{$S E B$} & \multirow[t]{2}{*}{$\beta$} & \multicolumn{2}{|c|}{$95 \% \mathrm{CI}$} & \multirow[t]{2}{*}{$B$} & \multirow[t]{2}{*}{$S E B$} & \multirow[t]{2}{*}{$\beta$} & \multicolumn{2}{|c|}{$95 \% \mathrm{CI}$} \\
\hline & & & & Low & High & & & & Low & High \\
\hline Intercept & 6.19 & .48 & & 5.25 & 7.13 & 6.27 & .51 & & 5.26 & 7.28 \\
\hline Non-voluntary a & $-1.14 * *$ & .29 & -.41 & -1.70 & -.57 & $-1.09 * *$ & .33 & -.37 & -1.75 & -.43 \\
\hline Female Age & -.01 & .01 & -.12 & -.04 & .01 & -.02 & .01 & -.17 & -.05 & .01 \\
\hline Male Education $\mathrm{b}$ & .12 & .24 & .04 & -.35 & .59 & -.21 & .24 & -.07 & -.69 & .26 \\
\hline Female & -.01 & .01 & -.08 & -.04 & .02 & .01 & .01 & .08 & -.01 & .04 \\
\hline \multicolumn{11}{|l|}{ Depression } \\
\hline Male Depression & -.01 & .01 & -.04 & -.03 & .02 & -.02 & .01 & -.15 & -.05 & .01 \\
\hline$R^{2}$ & \multicolumn{5}{|c|}{0.17} & \multicolumn{5}{|c|}{0.19} \\
\hline$F$ & \multicolumn{5}{|c|}{$10.80 * *$} & \multicolumn{5}{|c|}{$11.64 * *$} \\
\hline
\end{tabular}

Notes. Multiple imputations 50, because of missing data.

a reference category is voluntary

]b education reference category is no college education.

$* p<.05 . * * p<.01$. 
Table 5

Summary of Simple Regression Analyses for Variables Predicting Split Alliance for Males and Females

\begin{tabular}{|c|c|c|c|c|c|c|c|c|c|c|}
\hline \multirow[b]{3}{*}{ Variable } & \multicolumn{5}{|c|}{ Session Rating Scale } & \multicolumn{5}{|c|}{ Couple Therapeutic Alliance Scale } \\
\hline & \multirow[t]{2}{*}{$B$} & \multirow[t]{2}{*}{$S E B$} & \multirow[t]{2}{*}{$\operatorname{Exp}(B)$} & \multicolumn{2}{|c|}{$95 \% \mathrm{CI}$} & \multirow[t]{2}{*}{$B$} & \multirow[t]{2}{*}{$S E B$} & \multirow[t]{2}{*}{$\operatorname{Exp}(B)$} & \multicolumn{2}{|c|}{$95 \% \mathrm{CI}$} \\
\hline & & & & Low & High & & & & Low & High \\
\hline Intercept & .05 & .59 & 1.05 & .33 & 3.31 & -1.10 & 1.10 & .34 & .04 & 2.89 \\
\hline Non-voluntary a & $.72 *$ & .34 & $2.06^{*}$ & 1.06 & 4.00 & $1.16^{*}$ & .56 & $3.18^{*}$ & .10 & 10.10 \\
\hline Female Age & -.00 & .01 & .10 & .97 & 1.02 & -.02 & .03 & .98 & .93 & 1.03 \\
\hline Male Education $\mathrm{b}$ & -.19 & .30 & .83 & .46 & 1.47 & -.37 & .52 & .69 & .25 & 1.91 \\
\hline Female Depression & -.02 & .02 & .98 & .95 & 1.01 & -.04 & .03 & .96 & .91 & 1.01 \\
\hline Male Depression & -.01 & .02 & .99 & .96 & 1.03 & $-.07 *$ & .03 & $.93 *$ & .87 & .10 \\
\hline
\end{tabular}

